\title{
AN EXCERPT FROM \\ DYING FOR DUMMIES (2020)
}

A guide to the next stage of your life.

\section{BY NORMAN SPINRAD}

\section{INTRODUCTION}

It used to be that choosing how to die involved no complicated menu of alternatives. You waited for it to happen or you took your own life - and that was it. And if you didn't want to decide on how to dispose of the material remains, you didn't have to - you could just leave that choice to your next of kin. But scientific advances have created more interesting and much more positive post-mortem modes to choose from. That's the good news.

The bad news is that making the choice requires sophisticated technological knowledge that is beyond what the average person is likely to have. You must understand that the choice is, in effect, the most crucial one you have to make, not merely in your life but potentially for ever. And you need to realize that the consequences will not be assured, that post-mortem existence is not a matter of certainty, but a bet on the odds that each mode currently seems to offer.

So the purpose of Dying For Dummies is to allow the public at large to make this choice in an enlightened and informed manner by explaining those odds and the costs of each post-mortem mode of existence.

\section{CHAPTER ONE: THE CURRENT POSSIBILITIES}

There are currently three post-mortem modes to choose from:

1) Cryogenic freezing of either the whole body or just the head. This is the most expensive choice, because the cryogenic state must be maintained indefinitely until the technology to revive your body or at least your brain is developed, if ever. In addition, it would be best to be frozen before you are legally dead, but that is not legal in all jurisdictions. So, given the expense and the odds, this cannot be recommended for most people.

2) Creation of a cloned body with your own genome and a brain transfer from your original body into it. This surgery is already possible and is favoured by those who believe that consciousness or the so-called 'soul' is an artefact of the unique individual cerebral meatware. Although initially more expensive than cryogenic freezing, it is cheaper in the medium run but, as with any major operation,

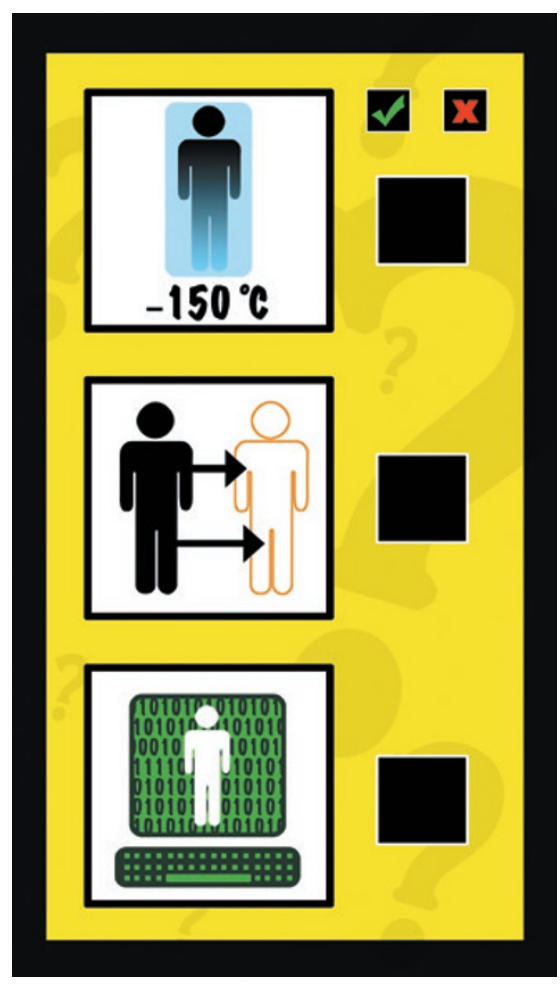

not without significant risk - and in the long run it is not a permanent solution, as the cloned body will eventually wear out too, and the procedure will have to be repeated.

Also, the choice of retaining the original cerebral meatware would seem to mean that the brain will continue to deteriorate in the cloned body or sequence of cloned bodies, although this has yet to be proved.

Still, this would be the obvious choice for those with religious or philosophical belief systems contending that if the 'soul, i.e. the consciousness software, is not running on the original meatware, 'you' are not really there.

3) Upload the instantaneous hologram of your consciousness and your memory data at or before the moment of death into a material matrix more robust than protoplasm - that is, computer hardware. Currently this seems to work to the point $\rightarrow$ NATURE.COM

Follow Futures: @ @NatureFutures f go.nature.com/mtoodm at which the 'entity' in the computer can easily enough pass a 'Familial Turing Test'. of the materially deceased speaks with the uploaded entity in the computer and with a synthesized emulation without being told which is which and correctly identifies the true post-mortem consciousness about 70\% of the time, significantly above random.

However, the technology to download the consciousness software in the computer to a cloned brain in a cloned body has not yet been perfected beyond experiments with simplified backups and with equivocal results. Some of the software entities in the computer hardware declare that they don't even want to be downloaded into disgusting squishy protoplasm and are more than content to wait until metal bodies become available. And some of them don't even want those 'bodies' to emulate protoplasmic human bodies, and instead are eager to become aeroplanes, spaceships, submarines and even more outré customized 'bodies.

This choice would seem to be the best one for those of modest means, as the upload to computer memory is the cheapest option, but it is probably only for the adventurous and those who believe that their essential being is the software of their consciousness independent of the meatware or hardware it is running on.

However, if consciousness is data and software independent of the meatware or hardware it is running on, it can be duplicated and backed up. But if it can be duplicated once, it can be duplicated many times and, once the technology is perfected, downloaded into multiple bodies, metallic creations, cloned protoplasm, or all of the above.

The practical advantages would be obvious. 'You' can be all the whatevers you want to be and at the same time. 'You' can be a whole football team, or a whole board of directors, or a whole symphony orchestra, or the whole population and machineries of an orbital habitat or otherwise generational starship.

So the question is:

\section{CHAPTER TWO: WHICH IS 'YOU'?}

... to be continued.

Norman Spinrad has been publishing novels in English for an actual half-century. His latest publication in English is the pamphlet Raising Hell. His latest novel has just been published in French as Police Du Peuple. 